\title{
Dual sensory loss and social participation in older Europeans
}

\author{
Anne Viljanen · Timo Törmäkangas • \\ Sonja Vestergaard · Karen Andersen-Ranberg
}

Published online: 1 October 2013

(C) Springer-Verlag Berlin Heidelberg 2013

\begin{abstract}
The purpose of the study was to describe the prevalence of hearing difficulties, vision difficulties and dual sensory difficulties in 11 European countries, and to study whether sensory difficulties are associated with social inactivity in older Europeans. This cross-sectional study is based on the 2004 data collection of the Survey of Health, Ageing and Retirement in Europe comprising 27,536 men and women aged 50 years and older. Hearing and vision difficulties, as well as participation in seven different social activities were assessed using a structured computerassisted personal interview. Logistic regression models were used for analyses. Altogether, $5.9 \%$ of the participants reported both hearing and vision difficulties (dual sensory loss), $10.2 \%$ vision difficulties only, and $13.5 \%$ hearing difficulties only. More than two-thirds $(68.6 \%)$ of the participants with dual sensory loss were socially inactive compared to half of those who reported no sensory difficulties. The participants who reported dual sensory loss had 2.18 (95\% CI 1.83-2.59) times higher odds for social inactivity compared to persons without hearing or vision difficulties. In a model adjusted for age, gender, mobility, depressive symptoms, cognition, education and wealth the corresponding odds ratio was 1.21 (95\% CI 1.00-1.47).
\end{abstract}

Responsible editor: H.-W. Wahl.

A. Viljanen $(\bowtie) \cdot T$. Törmäkangas

Gerontology Research Center and Department of Health

Sciences, University of Jyväskylä, P.O. Box 35 (Viveca), 40014 Jyväskylä, Finland

e-mail: anne.viljanen@jyu.fi

S. Vestergaard · K. Andersen-Ranberg Institute of Public Health, Epidemiology, University of Southern Denmark, Campusvej 55, 5230 Odense M, Denmark
According to our results, sensory difficulties were associated with social inactivity, but the higher likelihood for social inactivity among persons with sensory difficulties was attenuated by other health and socio-economic indicators. Our results suggest that various preventive and rehabilitative actions targeting older persons' sensory functions may enhance their social activity.

Keywords Ageing - Activity - Dual sensory loss · Hearing $\cdot$ Social participation $\cdot$ Vision

\section{Introduction}

An ageing population is one of the major challenges for Europe (Christensen et al. 2009). From the societal perspective, the active involvement of older people in society may constitute an additional economic and social resource. Older people may share their resources, for example by volunteering, by providing informal help to close ones, or by participating in different clubs or activities. From the personal perspective, social participation may have considerable positive effects on an individual's health and overall quality of life (European Commission 2011). For example, social inactivity has been linked to higher rates of depression (Chiao et al. 2011), cognitive decline (Glei et al. 2005), poorer physical functioning (Avlund et al. 2004a, b; Nilsson et al. 2011) and even mortality (Holt-Lunstad et al. 2010; Pynnönen et al. 2012). Active ageing may be achieved by promoting health and preventing health problems over the whole life-span, and by offering relevant support and opportunities for social contacts for persons who need them. From the preventive point of view, it is important to recognize factors that may lead to social inactivity. 
Social participation has been variously conceptualized. In this study, social participation describes a person's involvement in activities that provide interactions with others in society or the community (Levasseur et al. 2010). According to Wilkie et al. (2006) approximately half of those aged $50+$ years reported restricted participation in at least some aspect of life. Such restrictions increased with age, and were more commonly reported by women than men.

Sensory difficulties are common health concerns in older people, and the prevalence of impairments increases with ageing. Approximately every third person aged 60-70 years has impaired hearing (Gopinath et al. 2009; Hannula et al. 2011) and every fourth (Steinman and Allen 2012) has vision difficulties. Furthermore, approximately $1 \%$ of persons aged $60-69$ years, $5 \%$ of those aged 70-79 years, and as many as $27 \%$ of those aged 80-99 years report dual sensory loss, meaning that both hearing and vision are impaired (Schneider et al. 2012). However, it should be noted, that prevalence estimates vary widely between studies according to the subpopulations, methods, and specific definition of sensory impairment used (Heine and Browning 2002; Schneider et al. 2011). In older people, the most common diagnoses behind dual sensory loss are cataract or age-related macular degeneration in combination with presbycusis (Chia et al. 2006; Wittich et al. 2012).

Hearing and vision difficulties hinder access to environmental information and may also become an obstacle to communication, in turn isolating people, and jeopardizing their independence and overall well-being (Brennan and Bally 2007). Diminished sensory capacity also affects others. Because of difficulties in communication, others may avoid people with sensory difficulties, leaving them with even fewer opportunities for an active social life.

In previous studies, persons with vision loss had a twofold higher likelihood for social restriction compared to persons without vision loss (Wallhagen et al. 2001; Wilkie et al. 2007). According to the study by Alma et al. (2011), visually impaired persons aged 65 years or older participate in society, but because of vision loss, to a lesser degree than their non-impaired peers. The association between hearing and social activity has been weaker and less consistent than that for vision and activity (Wilkie et al. 2007) and not all studies support the association between poor hearing and social inactivity (Norris and Cunningham 1981; Wallhagen et al. 2001; Yamada et al. 2012).

Studies on the combined effect of vision and hearing loss on social activity are scarce. Crews and Campbell (2004) demonstrated a hierarchical pattern for the impact of sensory losses on daily activities and social participation. Participants with only hearing loss reported more often difficulties in daily activities and social participation than participants without hearing or vision difficulties. Participants with only vision difficulties reported even greater disparities, and those with both hearing and vision difficulties the greatest disparities.

Although vision and hearing difficulties in relation to social activities are studied in some extent, the knowledge about the combined effect of vision and hearing difficulties on social activity is very limited. The purpose of this study was, first, to describe the prevalence of hearing difficulties, vision difficulties and dual sensory difficulties in older Europeans. Second, the purpose was to study whether sensory difficulties are associated with social inactivity, and whether the association is similar or different across 11 European countries. This study is built upon the World Health Organization's International classification of functioning, disability and health-framework according to which decreased health, in this case sensory difficulties, in an interaction with different contextual factors, such as cultural or societal environment, may lead to participation restriction (World Health Organization 2001).

\section{Methods}

\section{Participants}

This study is based on the 2004 data collection of the Survey of Health, Ageing and Retirement in Europe (SHARE) comprising 27,536 men and women aged 50 years and older. SHARE data is based on representative samples drawn from population registers or from multistage sampling, i.e. regions were sampled first and then individuals selected within regions. SHARE is a multidisciplinary and cross-national longitudinal study which was conducted for the first time in 2004 in 11 European countries from Scandinavia, through Central Europe to the Mediterranean: Sweden, Denmark, Germany, the Netherlands, Belgium, France, Switzerland, Austria, Italy, Spain and Greece. The average household response rate was $61.6 \%$, ranging from $38.8 \%$ in Switzerland to $81.0 \%$ in France. SHARE database includes a great variety of information about health, socio-economics and social networks. The SHARE recruitment process and participation have been described in more detail elsewhere (Börsch-Supan and Jürges 2005).

\section{Procedures}

Data were collected using computer-assisted personal interviews by trained interviewers (Jürges 2005). Ethical approval for the SHARE was obtained from the University of Mannheim's internal review board, Germany, and all the participants gave their informed consent before the interview (Börsch-Supan and Jürges 2005). 


\section{Measures}

\section{Dependent variable: social activity}

Social activity was assessed with the yes/no question: "Have you done any of the listed activities in the last month?" (1) Done voluntary or charity work? (2) Cared for a sick or disabled adult? (3) Provided help to family, friends or neighbours? (4) Attended an educational or training course? (5) Gone to a sport, social or other kind of club? (6) Taken part in a religious organization (church, synagogue, mosque etc.)? (7) Taken part in a political or community-related organization? A person was rated as socially active if she/he had responded affirmatively to at least one of the listed activities and inactive otherwise.

\section{Independent variable: sensory difficulties}

Hearing was assessed with the question "Is your hearing [using a hearing aid as usual] excellent/very good/good/ fair/poor?" Vision was assessed with the question "Is your eyesight [using glasses or contact lenses as usual] excellent/very good/good/fair/poor/registered or legally blind?" Persons who rated their hearing as fair or poor were categorized as having hearing difficulties, and those who rated their vision as fair, poor or who were blind were categorized as having vision difficulties. Furthermore, all participants were categorized into one of four groups according to their hearing and vision status: (1) no hearing or vision difficulties, (2) hearing difficulties only, (3) vision difficulties only, and (4) hearing and vision difficulties (dual sensory loss).

\section{Descriptive variables}

Age was determined by calculating the difference between the interview year and birth year. Self-rated health was measured by the question "Would you say your health is excellent/very good/good/fair/poor?" Number of selfreported chronic diseases was calculated as a sum of the following 13 diseases diagnosed by a doctor: heart disease, high blood pressure, high blood cholesterol, stroke, diabetes, lung disease, asthma, arthritis, osteoporosis, cancer (excluding minor skin cancers), gastro-intestinal ulcer, Parkinson's disease, and hip or femoral fracture. A person was categorized as having depressive symptoms if she/he scored 4 or more points in a validated 12-item Eurodepression scale (Prince et al. 1999) and as having poor cognition if she/he remembered 3 or fewer words in the ten word list learning test (Dewey and Prince 2005).

A person was categorized as having limitation in activities of daily living (ADL) if she/he reported any difficulties with six basic activities such as dressing, eating, walking across the room, and having limitation in instrumental activities of daily living (IADL) if any difficulties with more demanding seven instrumental activities, such as preparing a hot meal, shopping for groceries, managing for money, were reported. Mobility was assessed according to the yes/no question "Because of a health problem, do you have difficulty walking $100 \mathrm{~m}$ ?", and fear of falling was assessed with the yes/no question "For the past 6 months at least, have you been bothered by fear of falling down?"

Educational level describes the highest level of the participant's completed formal education. To homogenize the country-specific educational categories, we reclassified the answers into three classes according to the 1997 International Standard Classification of Education (ISCED97). ISCED levels 0-2 correspond to lower secondary school at the most, level 3 upper secondary school and levels 4-6 post-secondary school (Avendano et al. 2009; United Nations Educational Scientific and Cultural Organization 2006).

Total annual household gross income describes the total income of all the members of the participant's household. Gross income was assessed as the sum of wages, selfemployment income, capital income, pensions and other payments, rent income, and long-term insurance payments. Total household net worth describes the sum of all financial and real assets. Financial assets derived from bank accounts, securities, mutual funds, individual retirement's accounts, contractual savings for housing, and life-insurance policies minus liabilities. Real assets were derived from the value of primary and other residences, own business and vehicles. Both the income and net worth variables were reported in Euros for all countries and adjusted for purchasing power parity (ppp). Missing items for income and wealth were imputed with the hot-deck method (Christelis et al. 2005a, b).

\section{Statistical analysis}

We applied respondent-level, cross-sectional, calibrated sampling weights in all analyses to account for the complex sampling design. Weights were calculated separately for each country and calibrated against the total national population by age and gender (De Luca and Rossetti 2011).

Design-based tests of independence were performed to analyse differences in the proportions of socially active and inactive participants with or without different health- and wealth-related characteristics. Similarly, mean differences in age, number of chronic diseases, gross income and net worth of socially active and inactive persons were tested using the adjusted Wald test.

Univariate logistic regression models were performed to analyse whether social activity was associated with sensory difficulties, and the health- and wealth-related 
characteristics. Multivariate logistic regression models for social inactivity were adjusted, first for age and gender, and second for age, gender, mobility, depression, cognition, educational status and financial status. In addition, the country-adjusted model was performed. Austria was selected arbitrarily as the reference country for analyses. This selection was also useful for the interpretation of results, because the prevalence of sensory difficulties, social activities as well as the most of the descriptive characteristics were there at the average level compared to the other countries.

The modelling was performed using Stata 12.0 statistical software (Stata Corp., College Station, TX, USA). $P$ values of $<0.05$ were considered statistically significant.

\section{Results}

Altogether $5.9 \%$ of the participants reported both hearing and vision difficulties (dual sensory loss), $10.2 \%$ vision difficulties only, and $13.5 \%$ hearing difficulties only. The prevalence of dual sensory loss varied from 1.6 to $10.3 \%$ across the 11 European countries, being lowest in Switzerland and highest in Italy (Table 1). According to a design-based test of independence, the occurrence of sensory difficulties differed in different countries $(p=0.000)$.

The most frequently reported social activities were helping family, friends or neighbours $(19.3 \%)$, and going to a sport, social or other club (19.5\%). Approximately half of the participants reported at least one of the listed seven social activities. Social activity was lowest in Spain $(26.2 \%)$ and Italy $(27.3 \%)$ and highest in Sweden $(64.1 \%)$. According to a design-based test of independence all the variables listed in Table 1, except gender, differed statistically significantly by social activity. Socially inactive persons were older, had poorer health and functional status, and had lower socio-economic status than socially active persons (Table 1 ).

More than two-thirds (68.6\%) of the participants with dual sensory loss were socially inactive compared to half of those who reported no sensory difficulties. From separate social activity domains, persons with dual sensory loss had the highest likelihood for social inactivity in attending educational or training course (OR 4.55, $95 \%$ CI 2.28-9.08), and taking part in political or community organizations (OR 4.59, $95 \%$ CI 2.62-8.03) compared to persons with no sensory difficulties. Taking part in religious organizations was approximately same among persons with or without sensory difficulties (Table 2).

Participants who reported dual sensory loss had 2.18 (95\% CI 1.83-2.59) times higher unadjusted odds for social inactivity compared to persons without hearing or vision difficulties. In Model 4, adjusted for age, gender, mobility, depression, cognition, education, and net worth, the corresponding OR was 1.21 (95\% CI 1.00-1.47). The OR was of the same magnitude as the OR of persons who reported vision difficulties only (OR 1.28, $95 \%$ CI 1.12-1.47). The ORs between sensory difficulties and social inactivity attenuated slightly when country was entered into Model 5 together with other adjusting variables.

In Sweden, Denmark, the Netherlands, Belgium, Switzerland and Greece, the country acts as a protective factor for social inactivity compared to Austria. In Italy and Spain the effect was opposite (Table 3).

In Fig. 1 country-stratified analyses for social inactivity according to sensory difficulties are shown. The trend towards higher probability for social inactivity in age, gender, mobility, depression, cognition, education, and wealth-adjusted models was most notable in Denmark and Spain, but it should be noted that the results varied widely across countries. The interactions of the country variable with sensory difficulties were non-significant (see Fig. 1; data for interaction tests not shown).

\section{Discussion}

According to this study, approximately every third European aged $50+$ years has difficulties either in hearing or seeing, or both. Social inactivity was most common among persons who had difficulties in both hearing and seeing, followed in order by those with vision difficulties only, hearing difficulties only, and least frequent among persons with no sensory difficulties. However, the higher likelihood for social inactivity among persons with sensory difficulties was attenuated by the other health and socio-economic indicators included in the analyses. Furthermore, it should be noted that the results varied across countries.

The prevalence of hearing, vision and dual sensory loss in this data are in accordance with the findings of Crews and Campbell (2004) among community dwelling participants aged 70 years and older $(n=9,447)$. Of their sample, $8 \%$ self-reported both vision and hearing loss, $10 \%$ vision loss only, $24 \%$ hearing loss only and $58 \%$ neither vision nor hearing loss. Our prevalence figures are slightly lower, which is probably due to the inclusion of younger participants in the study, as the prevalence of sensory difficulties increases with ageing (Schneider et al. 2011, 2012). In previous studies, poor visual acuity (Chia et al. 2006), particularly poorer vision for low-contrast targets (Schneck et al. 2012) was associated with higher likelihood for audiometrically assessed hearing impairment, the results further indicating that a deficit in one sensory domain increases the likelihood of a deficit in the other. It is important that clinicians, both audiologists and eye care practitioners, take this possibility into account (Brabyn et al. 2007; Schneck et al. 2012). 


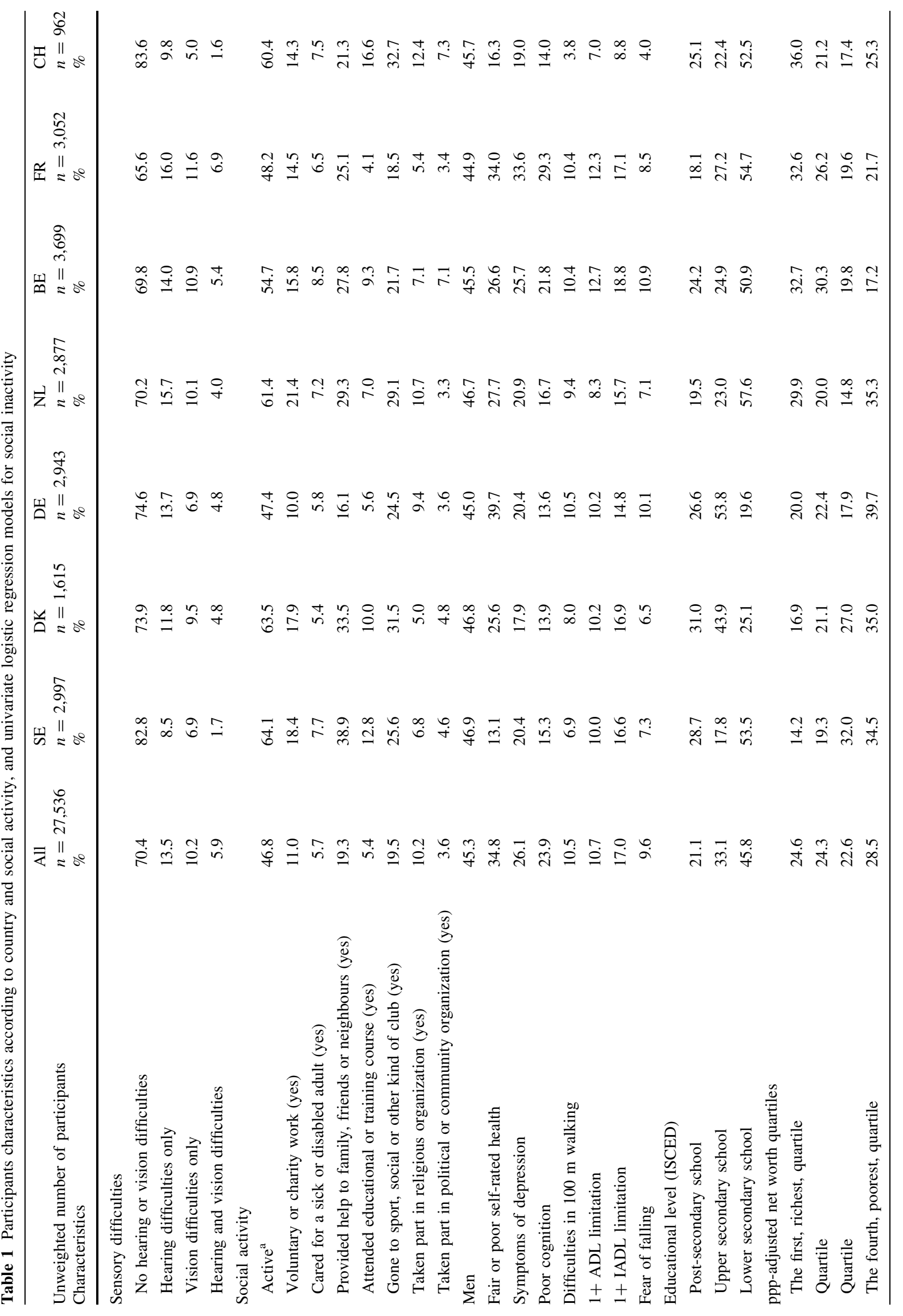




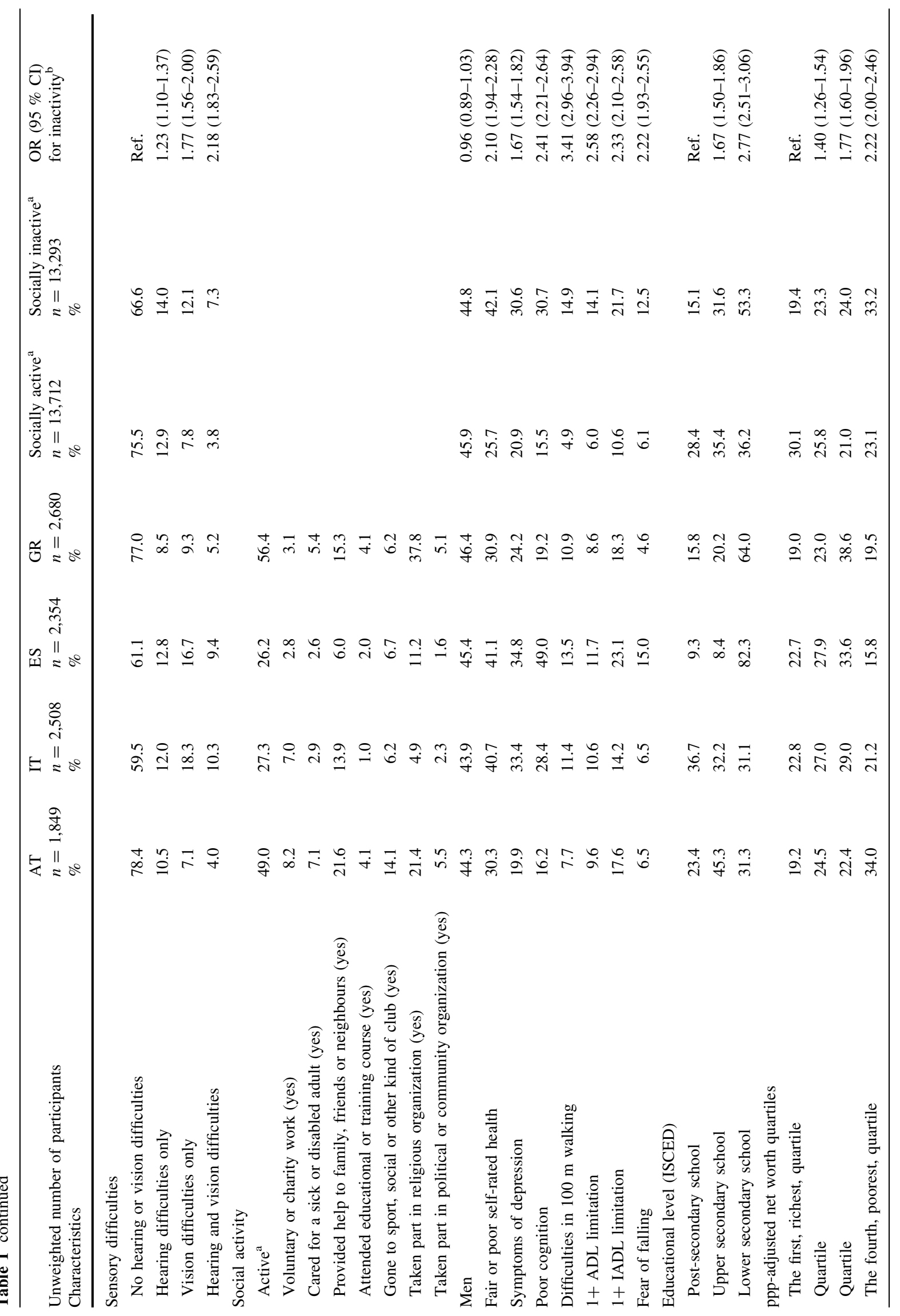




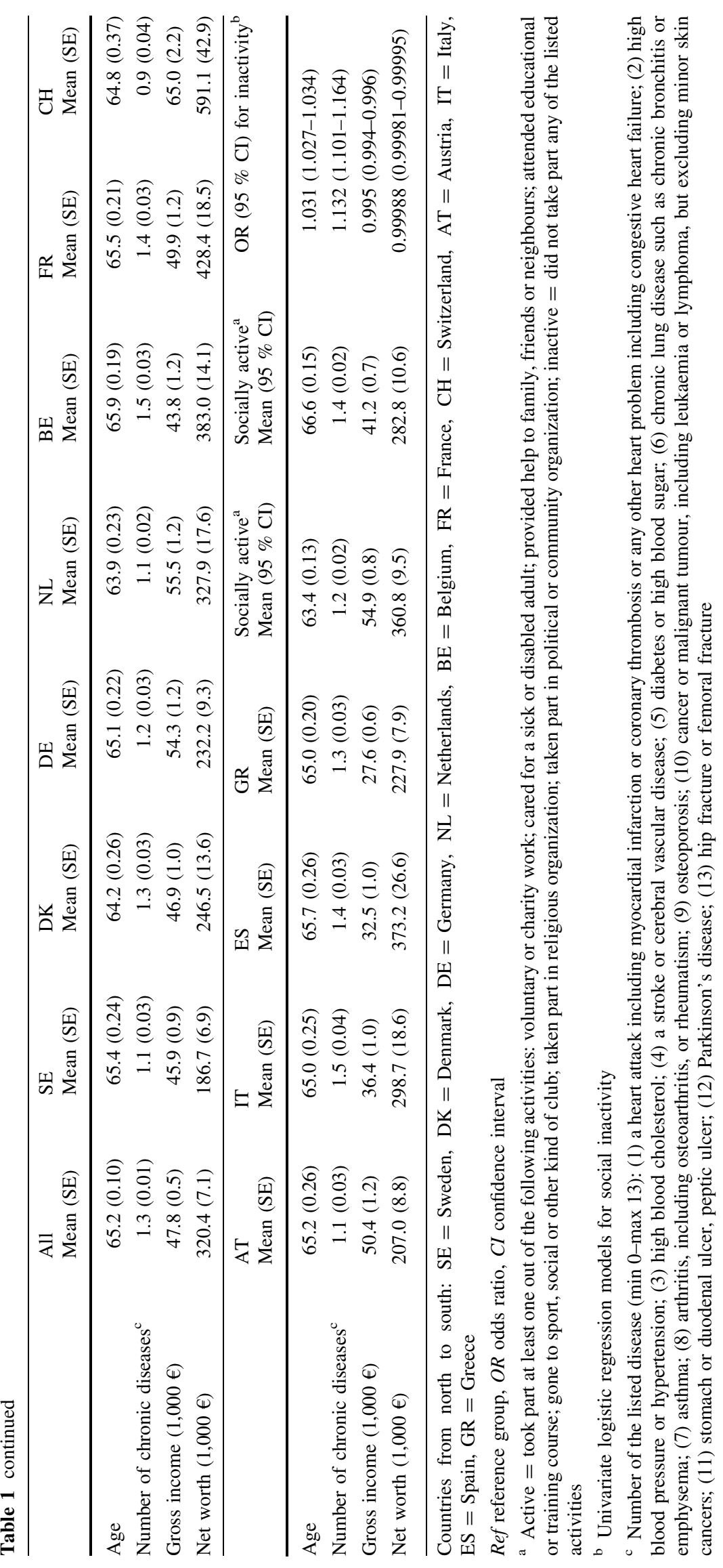


Table 2 Social activity according to sensory difficulties, and univariate logistic regression models for social inactivity

\begin{tabular}{|c|c|c|c|c|c|c|}
\hline & $\begin{array}{l}\text { Total } \\
\%\end{array}$ & $\begin{array}{l}\text { No sensory } \\
\text { difficulties } \\
\% \\
\text { Ref. }\end{array}$ & $\begin{array}{l}\text { Hearing } \\
\text { difficulties only } \\
\% \\
\text { OR }(95 \% \mathrm{CI})\end{array}$ & $\begin{array}{l}\text { Vision } \\
\text { difficulties only } \\
\% \\
\text { OR }(95 \% \mathrm{CI})\end{array}$ & $\begin{array}{l}\text { Hearing and } \\
\text { vision difficulties } \\
\% \\
\text { OR }(95 \% \mathrm{CI})\end{array}$ & $\begin{array}{l}\text { Design-based } \\
\text { test of } \\
\text { independence }\end{array}$ \\
\hline \multicolumn{7}{|l|}{ Social activity $(n=26,696)^{\mathrm{a}}$} \\
\hline Active & 46.8 & 49.9 & 44.8 & 36.1 & 31.4 & 0.000 \\
\hline \multirow[t]{2}{*}{ Inactive } & 53.2 & 50.1 & 55.2 & 63.9 & 68.6 & \\
\hline & & Ref. & $1.23(1.10-1.37)$ & $1.77(1.56-2.00)$ & $2.18(1.83-2.59)$ & \\
\hline \multirow{2}{*}{$\begin{array}{l}\text { Voluntary or charity } \\
\text { work (yes) }\end{array}$} & 11.0 & 11.9 & 11.1 & 7.6 & 5.4 & 0.000 \\
\hline & & Ref. & $1.09(0.92-1.27)$ & $1.65(1.34-2.03)$ & $2.36(1.67-3.33)$ & \\
\hline \multirow{2}{*}{$\begin{array}{l}\text { Cared for a sick or } \\
\text { disabled adult (yes) }\end{array}$} & 5.7 & 6.3 & 4.4 & 5.3 & 3.1 & 0.001 \\
\hline & & Ref. & $1.44(1.12-1.85)$ & $1.20(0.93-1.54)$ & $2.06(1.38-3.07)$ & \\
\hline \multirow{2}{*}{$\begin{array}{l}\text { Provided help to family, friends } \\
\text { or neighbours (yes) }\end{array}$} & 19.3 & 20.3 & 19.2 & 15.7 & 13.3 & 0.000 \\
\hline & & Ref. & $1.07(0.94-1.22)$ & $1.36(1.17-1.59)$ & $1.66(1.31-2.10)$ & \\
\hline \multirow{2}{*}{$\begin{array}{l}\text { Attended educational or training } \\
\text { course (yes) }\end{array}$} & 5.4 & 6.4 & 3.8 & 2.8 & 1.5 & 0.000 \\
\hline & & Ref. & $1.71(1.33-2.20)$ & $2.38(1.73-3.29)$ & $4.55(2.28-9.08)$ & \\
\hline \multirow{2}{*}{$\begin{array}{l}\text { Gone to sport, social or } \\
\text { other kind of club (yes) }\end{array}$} & 19.5 & 21.0 & 19.4 & 12.7 & 12.5 & 0.000 \\
\hline & & Ref. & $1.11(0.97-1.27)$ & $1.83(1.53-2.20)$ & $1.87(1.46-2.40)$ & \\
\hline \multirow{2}{*}{$\begin{array}{l}\text { Taken part in religious } \\
\text { organization (yes) }\end{array}$} & 10.2 & 10.5 & 10.4 & 8.8 & 8.8 & 0.195 \\
\hline & & Ref. & $1.01(0.85-1.20)$ & $1.21(0.99-1.48)$ & $1.21(0.90-1.63)$ & \\
\hline \multirow{2}{*}{$\begin{array}{l}\text { Taken part in political } \\
\text { or community } \\
\text { organization (yes) }\end{array}$} & 3.6 & 4.1 & 3.3 & 2.2 & 0.9 & 0.000 \\
\hline & & Ref. & $1.23(0.91-1.67)$ & $1.94(1.37-2.74)$ & $4.59(2.62-8.03)$ & \\
\hline
\end{tabular}

Ref reference group, $O R$ odds ratio, $C I$ confidence interval

${ }^{\text {a }}$ Active $=$ took part at least one out of the following seven activities; inactive $=$ did not take part any of the following activities

The hierarchical pattern of the impact of sensory difficulties on social inactivity was in line with previously reported results. Crews and Campbell (2004) demonstrated that persons with hearing and vision loss were least likely to visit friends, eat out at a restaurant, attend church, attend movies, or engage in exercise, followed in order by participants with vision loss only, hearing loss only and no sensory loss. However, there were no differences between the sensory groups in visiting relatives. The same hierarchical pattern has been even clearer between sensory difficulties and daily activities (Crews and Campbell 2004). After multivariable adjustment, the hierarchical pattern of sensory functions vanished in our study, indicating that vision has a more important impact on social activity than hearing. Persons with only vision difficulties had even a slightly higher likelihood for social inactivity than persons with dual sensory loss. A similar pattern was observed in previous studies for the association between sensory functions and activities of daily living (Brennan et al. 2005, 2006; Lin et al. 2004) and between sensory functions and functional activity (Harada et al. 2008), the increased risk from dual sensory loss being of the same magnitude as that reported by persons with vision loss alone, while hearing difficulties alone did not increase the risk for difficulties in daily living compared to those who reported no sensory difficulty.
Recently, there has been growing interest in crossnational comparative ageing research (Tesch-Römer and von Kondratowitz 2006). Although age-related decreases in vision and hearing are more or less universal phenomena among older persons, there may be substantial differences across countries in treatment of possible underlying diseases or in rehabilitative actions, which may lead to differences in coping with vision or hearing difficulties in everyday life. It is also presumable that participation in separate out-of-home social activities may at least partly be culture- and society-dependent and social activity offerings, both quality and quantity, may substantially differ across and even within countries. Results of this study evinced large country-specific differences in predictor levels, and also the results about the adjusted associations between sensory difficulties and social participation differed in different countries. These country-specific differences attenuated the overall estimate of the effect of sensory difficulty on social inactivity. The trend towards higher probability for social inactivity with increasing sensory difficulties was most notable in Denmark and Spain. Country-specific differences in measures of health and socio-economic status tended to have a large effect on the social activity outcome, resulting in a lower odds estimate for sensory difficulties in the pooled-data analysis. 
Table 3 Logistic regression models for social inactivity

\begin{tabular}{|c|c|c|c|c|c|}
\hline Characteristics & $\begin{array}{l}\text { Model } 1 \\
\text { OR }(95 \% \mathrm{CI})\end{array}$ & $\begin{array}{l}\text { Model } 2 \\
\text { OR }(95 \% \mathrm{CI})\end{array}$ & $\begin{array}{l}\text { Model } 3 \\
\text { OR }(95 \% \text { CI })\end{array}$ & $\begin{array}{l}\text { Model } 4 \\
\text { OR }(95 \% \text { CI })\end{array}$ & $\begin{array}{l}\text { Model } 5 \\
\text { OR }(95 \% \text { CI })\end{array}$ \\
\hline \multicolumn{6}{|l|}{ Sensory difficulties } \\
\hline No hearing or vision difficulties & Ref. & Ref. & Ref. & Ref. & Ref. \\
\hline Hearing difficulties only & $1.23(1.10-1.37)$ & $1.06(0.95-1.19)$ & $0.97(0.87-1.09)$ & $0.96(0.86-1.08)$ & $0.96(0.85-1.08)$ \\
\hline Vision difficulties only & $1.77(1.56-2.00)$ & $1.61(1.42-1.82)$ & $1.35(1.19-1.54)$ & $1.28(1.12-1.47)$ & $1.20(1.04-1.37)$ \\
\hline Hearing and vision difficulties & $2.18(1.83-2.59)$ & $1.69(1.42-2.02)$ & $1.26(1.04-1.51)$ & $1.21(1.00-1.47)$ & $1.10(0.91-1.34)$ \\
\hline Age (years) & & $1.03(1.02-1.03)$ & $1.02(1.01-1.02)$ & $1.01(1.006-1.015)$ & $1.01(1.01-1.02)$ \\
\hline Male & & $1.03(0.96-1.11)$ & $1.08(1.00-1.16)$ & $1.17(1.08-1.26)$ & $1.17(1.08-1.27)$ \\
\hline Difficulties in $100 \mathrm{~m}$ walking & & & $2.18(1.86-2.54)$ & $2.00(1.71-2.34)$ & $2.00(1.71-2.35)$ \\
\hline Symptoms of depression & & & $1.32(1.20-1.45)$ & $1.25(1.14-1.38)$ & $1.22(1.11-1.34)$ \\
\hline Poor cognition & & & $1.82(1.65-2.00)$ & $1.57(1.42-1.74)$ & $1.33(1.20-1.47)$ \\
\hline \multicolumn{6}{|l|}{ Education (ISCED) } \\
\hline Post-secondary school & & & & Ref. & Ref. \\
\hline Upper secondary school & & & & $1.52(1.36-1.69)$ & $1.52(1.36-1.70)$ \\
\hline Lower secondary school & & & & $1.97(1.77-2.18)$ & $1.91(1.70-2.14)$ \\
\hline \multicolumn{6}{|l|}{ ppp-adjusted net worth quartiles } \\
\hline The first, richest, quartile & & & & Ref. & Ref. \\
\hline The second quartile & & & & $1.21(1.09-1.34)$ & $1.18(1.06-1.31)$ \\
\hline The third quartile & & & & $1.38(1.24-1.54)$ & $1.36(1.22-1.53)$ \\
\hline The fourth, poorest, quartile & & & & $1.69(1.52-1.89)$ & $1.82(1.62-2.03)$ \\
\hline \multicolumn{6}{|l|}{ Country } \\
\hline Austria & & & & & Ref. \\
\hline Sweden & & & & & $0.49(0.43-0.56)$ \\
\hline Denmark & & & & & $0.55(0.47-0.63)$ \\
\hline Germany & & & & & $1.08(0.95-1.22)$ \\
\hline Netherlands & & & & & $0.54(0.48-0.62)$ \\
\hline Belgium & & & & & $0.77(0.67-0.87)$ \\
\hline France & & & & & $0.94(0.82-1.07)$ \\
\hline Switzerland & & & & & $0.66(0.56-0.78)$ \\
\hline Italy & & & & & $2.68(2.28-3.15)$ \\
\hline Spain & & & & & $2.15(1.83-2.53)$ \\
\hline Greece & & & & & $0.65(0.57-0.75)$ \\
\hline
\end{tabular}

Ref reference group, $O R$ odds ratio, $C I$ confidence interval

Whether these differences are due to measurement, or study participation, or reflect cultural characteristics, require further study.

The causality and complexity of the relations between deteriorated mental or physical health and social inactivity are currently under active debate. It has been demonstrated, for example that depression can cause social inactivity, and, conversely, that social inactivity can lead to depression (Chiao et al. 2011; Isaac et al. 2009; Wilkie et al. 2007). The cross-sectional design did not permit the causality between sensory functions and social activity to be confirmed in this study, but it seems reasonable to assume that sensory difficulties lead to social inactivity rather than vice versa. Our results offer suggestive evidence that depressive symptoms, poor cognition and poor mobility may act as mediators between sensory difficulties and social inactivity. Previous studies have demonstrated a link between sensory difficulties and depressive symptoms (Harada et al. 2008; McDonnall 2011), cognitive decline (Lin et al. 2004) and mobility decline (Viljanen et al. 2009, 2012), all of which are also linked to social inactivity (Avlund et al. 2004a, b; Chiao et al. 2011; Glei et al. 2005; Nilsson et al. 2011). Another pathway, although not supported in our study, is that sensory difficulties lead directly to decreased participation (Crews and Campbell 2004), and that this is the reason for the decline in physical and mental capacity (Avlund et al. 2004a, b; Chiao et al. 2011; Glei et al. 2005; Nilsson et al. 2011).

A person with a single sensory impairment may compensate for the decrement in functioning by greater reliance 


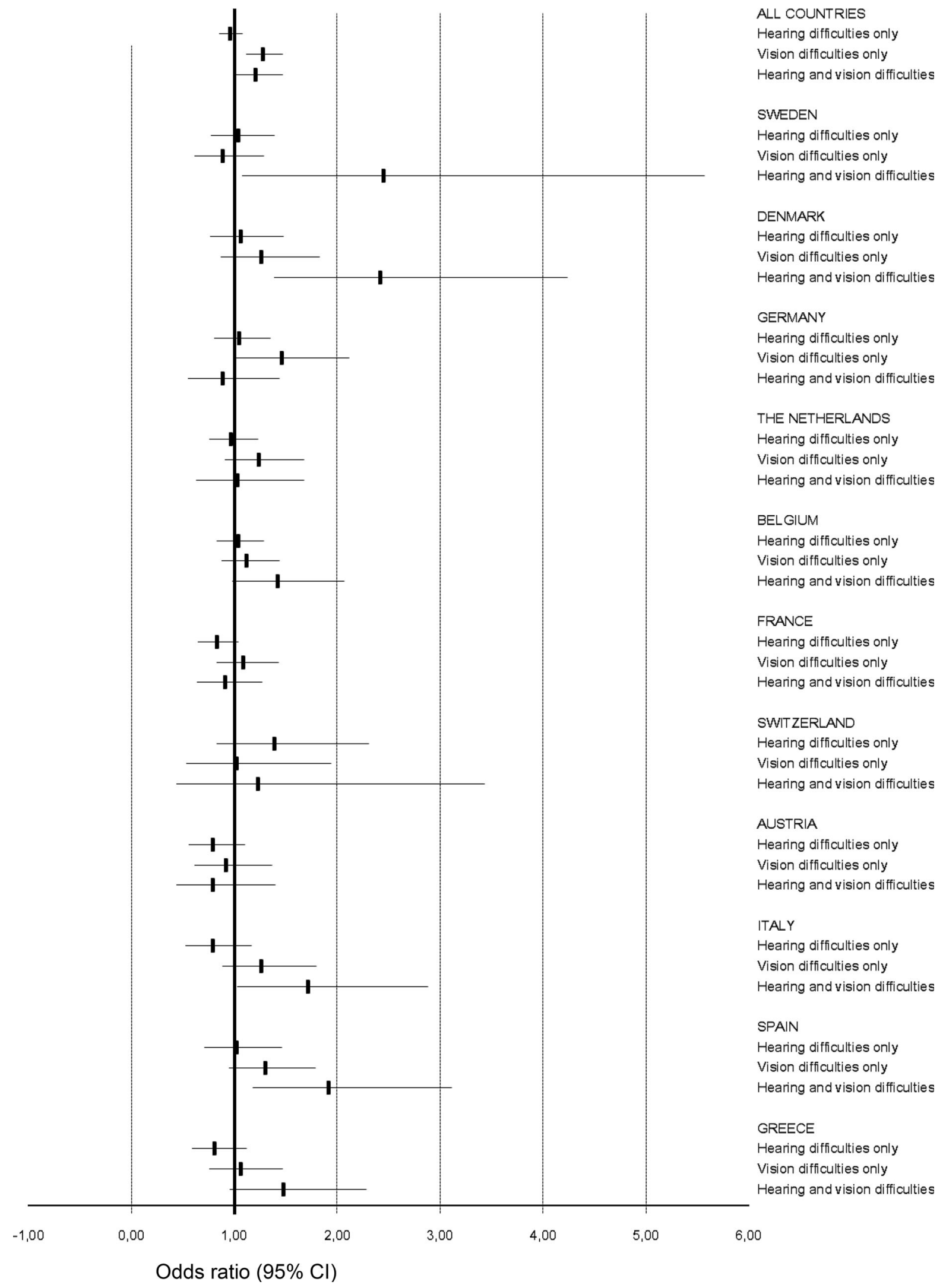

Fig. 1 Odds ratios and their $95 \%$ confidence intervals for social inactivity according to sensory difficulties by country. Logistic regression models are adjusted for age, gender, difficulties in walking $100 \mathrm{~m}$, depressive symptoms, poor cognition, education and wealth 
on the other sensory domains; but when multiple sensory impairments accumulate, such a compensatory resource will be lost (Merabet and Pascual-Leone 2010). Consequently, while intuitively it might be presumed that dual sensory loss has an additive, or even a synergistic impact on the affected person's everyday functioning and social activity, this has not been conclusively demonstrated (Brennan et al. 2005; Crews and Campbell 2004; Lee et al. 1999; Lin et al. 2004). It is possible that persons with severe sensory problems, and particularly severe dual sensory loss, are unwilling to participate in studies because of possible communication problems. If so, this would attenuate the results on the association between dual sensory loss and social activity. It is also possible that the questions and questionnaires currently in use, which have been designed to estimate the disabling effects of a single sensory impairment only, are unable to capture the possible effects of dual sensory loss on performance in tasks and situations which are particularly challenging for persons with both hearing and vision difficulties (Saunders and Echt 2007).

Some social activities may not be captured by the questionnaire used, and we do not know precisely what the participant's role is in an activity. Sensory impaired persons may take a more passive role in activities than nonimpaired peers, or select activities which make fewer demands on communication. Our results indicate that persons with dual sensory loss had the highest likelihood for inactivity in an attending educational or training course or taking part in political or community organizations, which can be assumed to require the highest communication abilities of the activities on the list. Moreover, we do not have more specific information on the kinds of clubs people are active in. Various clubs and community groups are organized specifically for hearing and/or vision impaired persons, but their availability may vary widely across regions, which may be one reason behind the differences across countries found in this study. Our results support previous findings that persons may be socially active despite having sensory disabilities. For example, participation in religious activities was of the same magnitude whether or not the person reported sensory difficulties. This result is in line with the findings of Alma et al. (2011), who demonstrated that religious activity is equally common among vision impaired and non-impaired older person. Stratified analysis according to productive social activity (voluntary work, caring for a sick or disabled adult, helping family, friends or neighbours) and collective social activity (participation in an educational or training course, sport, social or other club, religious organization, political or community-related organization) (Bukov et al. 2002) were also conducted as a part of this study (results not shown). The main results on the associations between sensory difficulties and productive or collective social activities were very similar to each other and comparable to the results presented here for combined social activity.

The results of this study are based on self-reports of vision and hearing. Perceived and objectively assessed sensory functions are more or less related, depending on the methods used, but they may capture different dimensions of functioning, and thus should be considered complementary rather than measures of the same trait. Selfreports provide information about perceived difficulties in the everyday environment, and are thus clinically highly relevant and suitable for the analysis of the association between sensory functions and social participation (Brennan et al. 2006; Horowitz et al. 2005; Kiely et al. 2012).

Some main limitations of the present study should be acknowledged in the interest of future research. Firstly, this study is based on self-reports about hearing and vision difficulties and no objective data about sensory functions were available. Although, less feasible when used in a large study including more than 25,000 individuals, comparative objective sensory data could have reduced some possible cultural differences related to self-report data. Secondly, social activity was also based on self-reports and no specific data about the more precise nature of activities were available. It is also possible, that not all activities were captured with a seven-item question.

\section{Conclusions}

This study focused on a highly topical issue in a rapidly ageing Europe. According to our results, approximately every third older European has difficulties either in hearing or seeing, or both. Sensory difficulties were associated with social inactivity, but the higher likelihood for social inactivity among persons with sensory difficulties was attenuated by other health and socio-economic indicators. The results about the association between sensory difficulties and social inactivity differed across European countries. Further studies are needed to explore in detail those cultural or community-related features which seem to either facilitate or inhibit the social activity. Qualitative approach to sensory impaired persons perceived activity restrictions might offer an interesting perspective on the topic. From the preventive point of view, it would be important, first, to identify people who are at high risk for social inactivity, and, second, to find ways of promoting active ageing. Our results offer suggestive evidence that different preventive and rehabilitative actions targeting sensory functions in older persons may enhance their social activity, but this should be affirmed using case-control studies. Attention should be paid in particular to persons who have both hearing and vision loss, and their special needs should be 
recognized. Furthermore, studies are needed on whether environmental modifications, aimed especially at improving visual and acoustic factors, could enhance the social participation of sensory impaired persons.

Acknowledgments This paper uses data from SHARE wave 1 release 2.5.0, as of May 24th 2011. The SHARE data collection has been primarily funded by the European Commission through the 5 th Framework Programme (project QLK6-CT-2001-00360 in the thematic programme Quality of Life), through the 6th Framework Programme (projects SHARE-I3, RII-CT-2006-062193, COMPARE, CIT5-CT-2005-028857, and SHARELIFE, CIT4-CT-2006-028812) and through the 7th Framework Programme (SHARE-PREP, No 211909, SHARE-LEAP, No 227822 and SHARE M4, No 261982). Additional funding from the US National Institute on Aging (U01 AG09740-13S2, P01 AG005842, P01 AG08291, P30 AG12815, R21 AG025169, Y1-AG-4553-01, IAG BSR06-11 and OGHA 04-064) and the German Ministry of Education and Research as well as from various national sources is gratefully acknowledged (see www.shareproject.org for a full list of funding institutions). This study was financially supported by the Academy of Finland (Grant numbers 251723, 263729 to AV).

\section{References}

Alma MA, van der Mei SF, Melis-Dankers BJ, van Tilburg TG, Groothoff JW, Suurmeijer TP (2011) Participation of the elderly after vision loss. Disabil Rehabil 33:63-72

Avendano M, Jürges H, Mackenbach JP (2009) Educational level and changes in health across Europe: longitudinal results from SHARE. J Eur Soc Policy 19:301-316

Avlund K, Lund R, Holstein BE, Due P (2004a) Social relations as determinant of onset of disability in aging. Arch Gerontol Geriatr 38:85-99

Avlund K, Lund R, Holstein BE, Due P, Sakari-Rantala R, Heikkinen RL (2004b) The impact of structural and functional characteristics of social relations as determinants of functional decline. J Gerontol B Psychol Sci Soc Sci 59:S44-S51

Börsch-Supan A, Jürges H (eds) (2005) The survey of health, aging, and retirement in Europe: methodology. Mannheim Research Institute for the Economics of Aging, Mannheim

Brabyn JA, Schneck ME, Haegerstrom-Portnoy G, Lott LA (2007) Dual sensory loss: overview of problems, visual assessment, and rehabilitation. Trends Amplif 11:219-226

Brennan M, Bally SJ (2007) Psychosocial adaptations to dual sensory loss in middle and late adulthood. Trends Amplif 11:281-300

Brennan M, Horowitz A, Su Y (2005) Dual sensory loss and its impact on everyday competence. Gerontologist 45:337-346

Brennan M, Su YP, Horowitz A (2006) Longitudinal associations between dual sensory impairment and everyday competence among older adults. J Rehabil Res Dev 43:777-792

Bukov A, Maas I, Lampert T (2002) Social participation in very old age: cross-sectional and longitudinal findings from BASE. Berlin aging study. J Gerontol B Psychol Sci Soc Sci 57:P510-P517

Chia EM, Mitchell P, Rochtchina E, Foran S, Golding M, Wang JJ (2006) Association between vision and hearing impairments and their combined effects on quality of life. Arch Ophthal 124:1465-1470

Chiao C, Weng LJ, Botticello AL (2011) Social participation reduces depressive symptoms among older adults: an 18-year longitudinal analysis in Taiwan. BMC Public Health 11:292

Christelis D, Jappelli T, Padula M (2005a) Generated asset variables in SHARE Release 1. In: Börsch-Supan A, Jürges H (eds) The survey of health, aging and retirement in Europe: methodology. Mannheim Research Institute for the Economics of Ageing, Mannheim, pp 114-127

Christelis D, Jappelli T, Padula M (2005b) Wealth and portfolio composition. In: Börsch-Supan A, Brugiavini A, Jürges $\mathrm{H}$, Mackenbach JP, Siegrist J, Weber G (eds) Health, ageing and retirement in Europe: first results from the survey of health. Research Institute for the Economics of Ageing, Mannheim, pp 310-317

Christensen K, Doblhammer G, Rau R, Vaupel J (2009) Ageing populations: the challenges ahead. Lancet 374:1196-1208

Crews JE, Campbell VA (2004) Vision impairment and hearing loss among community-dwelling older Americans: implications for health and functioning. Am J Public Health 94:823-829

De Luca G, Rossetti C (2011) Weights in the first three waves of SHARE. SHARE Survey of health, ageing and retirement in Europe. Release guide 2.5.0. Waves $1 \&$ 2. Mannheim Research Institute for the Economics of Aging, Mannheim, pp 40-47

Dewey M, Prince M (2005) Cognitive function. In: Börsch-Supan A, Brugiavini A, Jürges H, Mackenbach J, Siegrist J, Weber G (eds) Health, ageing and retirement in Europe: first results from the survey of health, ageing and retirement in Europe. Mannheim Research Institute for the Economics of Ageing, Mannheim, pp 118-125

European Commission (2011) Active ageing and solidarity between generations: a statistical portrait of the European Union 2012. Publications Office of the European Union, Luxembourg

Glei DA, Landau DA, Goldman N, Chuang YL, Rodriguez G, Weinstein M (2005) Participating in social activities helps preserve cognitive function: an analysis of a longitudinal, population-based study of the elderly. Int J Epidemiol 34:864-871

Gopinath B, Rochtchina E, Wang JJ, Schneider J, Leeder SR, Mitchell P (2009) Prevalence of age-related hearing loss in older adults: Blue Mountains study. Arch Intern Med 169:415-416

Hannula S, Bloigu R, Majamaa K, Sorri M, Mäki-Torkko E (2011) Self-reported hearing problems among older adults: prevalence and comparison to measured hearing impairment. J Am Acad Audiol 22:550-559

Harada S, Nishiwaki Y, Michikawa T et al (2008) Gender difference in the relationships between vision and hearing impairments and negative well-being. Prev Med 47:433-437

Heine C, Browning CJ (2002) Communication and psychosocial consequences of sensory loss in older adults: overview and rehabilitation directions. Disabil Rehabil 24:763-773

Holt-Lunstad J, Smith TB, Layton JB (2010) Social relationships and mortality risk: a meta-analytic review. PLoS Med 7:e1000316

Horowitz A, Brennan M, Reinhardt JP (2005) Prevalence and risk factors for self-reported visual impairment among middle-aged and older adults. Res Aging 27:307-326

Isaac V, Stewart R, Artero S, Ancelin ML, Ritchie K (2009) Social activity and improvement in depressive symptoms in older people: a prospective community cohort study. Am J Geriatr Psychiatry 17:688-696

Jürges H (2005) Interview, module, and question length in SHARE. In: Börsch-Supan A, Jürges H (eds) The survey of health, aging, and retirement in Europe: methodology. Mannheim Research Institute for the Economics of Aging, Mannheim, pp 82-87

Kiely KM, Gopinath B, Mitchell P, Browning CJ, Anstey KJ (2012) Evaluating a dichotomized measure of self-reported hearing loss against gold standard audiometry: prevalence estimates and age bias in a pooled national data set. J Aging Health 24:439-458

Lee P, Smith JP, Kington R (1999) The relationship of self-rated vision and hearing to functional status and well-being among seniors 70 years and older. Am J Ophthalmol 127:447-452

Levasseur M, Richard L, Gauvin L, Raymond E (2010) Inventory and analysis of definitions of social participation found in the aging 
literature: proposed taxonomy of social activities. Soc Sci Med 71:2141-2149

Lin MY, Gutierrez PR, Stone KL, Yaffe K, Ensrud KE, Fink HA et al (2004) Vision impairment and combined vision and hearing impairment predict cognitive and functional decline in older women. J Am Geriatr Soc 52:1996-2002

McDonnall MC (2011) Physical status as a moderator of depressive symptoms among older adults with dual sensory loss. Rehabil Psychol 56:67-76

Merabet L, Pascual-Leone A (2010) Neural reorganization following sensory loss: the opportunity of change. Nat Rev Neurosci 11:44-52

Nilsson CJ, Avlund K, Lund R (2011) Onset of mobility limitations in old age: the combined effect of socioeconomic position and social relations. Age Ageing 40:607-614

Norris ML, Cunningham DR (1981) Social impact of hearing loss in the aged. J Gerontol 36:727-729

Prince MJ, Reischies F, Beekman AT, Fuhrer R, Jonker C, Kivelä SL et al (1999) Development of the EURO-D scale: a European, Union initiative to compare symptoms of depression in 14 European centres. Br J Psychiatry 174:330-338

Pynnönen K, Törmäkangas T, Heikkinen RL, Rantanen T, Lyyra TM (2012) Does social activity decrease risk for institutionalization and mortality in older people? J Gerontol B Psychol Sci Soc Sci 67:765-774

Saunders GH, Echt KV (2007) An overview of dual sensory impairment in older adults: perspectives for rehabilitation. Trends Amplif 11:243-258

Schneck ME, Lott LA, Haegerstrom-Portnoy G, Brabyn JA (2012) Association between hearing and vision impairments in older adults. Ophthalmic Physiol Opt 32:45-52

Schneider JM, Gopinath B, McMahon CM, Leeder SR, Mitchell P, Wang JJ (2011) Dual sensory impairment in older age. J Aging Health 23:1309-1324

Schneider J, Gopinath B, McMahon C, Teber E, Leeder SR, Wang JJ, Mitchell P (2012) Prevalence and 5-year incidence of dual sensory impairment in an older Australian population. Ann Epidemiol 22:295-301
Steinman BA, Allen SM (2012) Self-reported vision impairment and its contribution to disability among older adults. J Aging Health 24:307-322

Tesch-Römer C, von Kondratowitz H-J (2006) Comparative ageing research: a flourishing field in need of theoretical cultivation. Eur J Ageing 3:155-167

United Nations Educational Scientific and Cultural Organization (2006) International standard classification of education-ISCED 1997. Re-edition (2006) http://www.uis.unesco.org/ Library/Documents/isced97-en.pdf. Accessed 25 March 2013

Viljanen A, Kaprio J, Pyykkö I, Sorri M, Koskenvuo M, Rantanen T (2009) Hearing acuity as a predictor of walking difficulties in older women. J Am Geriatr Soc 57:2282-2286

Viljanen A, Kulmala J, Rantakokko M, Koskenvuo M, Kaprio J, Rantanen $T$ (2012) Fear of falling and coexisting sensory difficulties as predictors of mobility decline in older women. J Gerontol A Biol Sci Med Sci 67:1230-1237

Wallhagen MI, Strawbridge WJ, Shema SJ, Kurata J, Kaplan GA (2001) Comparative impact of hearing and vision impairment on subsequent functioning. J Am Geriatr Soc 49:1086-1092

Wilkie R, Peat G, Thomas E, Croft P (2006) The prevalence of person-perceived participation restriction in community-dwelling older adults. Qual Life Res 15:1471-1479

Wilkie R, Peat G, Thomas E, Croft P (2007) Factors associated with participation restriction in community-dwelling adults aged 50 years and over. Qual Life Res 16:1147-1156

Wittich W, Watanabe DH, Gagne J (2012) Sensory and demographic characteristics of deaf blindness rehabilitation clients in Montreal, Canada. Ophthalmic Physiol Opt 32:242-251

World Health Organization (2001) International classification of functioning, disability and health. World Health Organization, Geneva

Yamada M, Nishiwaki Y, Michikawa T, Takebayashi T (2012) Selfreported hearing loss in older adults is associated with future decline in instrumental activities of daily living but not in social participation. J Am Geriatr Soc 60:1304-1309 